\title{
LA IMPOSIBILIDAD DE CONSENTIR QUE LA DISCAPACIDAD SEA TOMADA COMO UN OBSTÁCULO PARA LA ESCUCHA DE NIÑOS, NIÑAS Y ADOLESCENTES EN EL PROCESO JUDICIAL
}

\section{THE IMPOSSIBILITY OF CONSENTING THE DISABILITY TO BE TAKEN AS AN OBSTACLE TO THE LISTENING OF CHILDREN AND ADOLESCENTS IN THE JUDICIAL PROCESS}

Clyris Marianela Chavez ${ }^{1}$

DOI: https://doi.org/10.37767/2591-3476(2021)23

Comentario a

L. H.,M. A. C/ F., A. E. S/ CUIDADO PERSONAL(f) (S / CASACION)

Poder Judicial de la Provincia de Río Negro

Disponible en

https://shortest.link/JQL

RESUMEN:

En el fallo, objeto del presente análisis, el Supremo Tribunal de Justicia de Río Negro, tacha de nula la sentencia de la Cámara de Apelaciones en lo Civil, Comercial, Familia y de Minería por haberse dictado sin escuchar al adolescente y se ordena que la misma tenga lugar antes de dictarse una nueva resolución ajustada a derecho. Así las cosas, el presente trabajo, pretende ilustrar a cerca de la gravedad que puede constituir negar derechos de raigambre constitucional como lo es el derecho de Niños, Niñas y Adolescentes a ser escuchado y que su opinión sea tenida en cuenta en cuestiones que los afectan directamente y más aún fundar dicha negativa en la discapacidad del menor, lo cual resulta de lleno incompatible con el diseño actual de discapacidad basado en los derechos humanos y en la igualdad inclusiva al que se asiste. 


\begin{abstract}
In the ruling, object of this analysis, the Supreme Court of Justice of Río Negro, nullifies the sentence of the Chamber of Appeals in Civil, Commercial, Family and Mining matters for having been handed down without listening to the adolescent and orders that it takes place before issuing a new resolution adjusted to the law. Thus, this work aims to illustrate the seriousness that denying rights of constitutional roots such as the right of Boys, Girls and Adolescents to be heard and that their opinion be taken into account in matters that affect them can constitute. directly and even more so to base said refusal on the minor's disability, which is completely incompatible with the current design of disability based on human rights and on the inclusive equality that is attended.
\end{abstract}

PALABRAS CLAVE: Participación de los niños, niñas y adolescentes en los procesos judiciales- derecho a ser oído y discapacidad- Convención Internacional sobre los Derechos del Niño- Convención sobre los derechos de las personas con discapacidad.

KEY WORDS: Participation of children and adolescents in judicial processes- right to be heard and disability- International Convention on the Rights of the Child- Convention on the Rights of Persons with Disabilities.

\title{
I. Introducción
}

Con la reforma constitucional de 1994, la exigencia de tener en cuenta el interés del menor en todos los actos judiciales y/o administrativos, adquirió rango constitucional. La Convención sobre los Derechos del Niño, adoptada el 20 de noviembre de 1989 y aprobada por la Ley 23.849 por la República Argentina el 22 de octubre de 1990, obtuvo jerarquía constitucional por imperio del primer párrafo del Art. 75 inc. 22 del nuevo texto constitucional. También se introdujo, con la referida reforma constitucional, el inc. 23 del Art. 75 el cuál determinó que corresponde al Congreso la adecuación de la legislación, hasta entonces vigente, y la sanción de las normas nuevas que garantizaran la totalidad de los derechos que el nuevo texto reconocía. Igual obligación se desprende del Art. 4 de la Convención sobre los Derechos del Niño. Así, en el orden nacional se sancionó, aunque algunos años posteriores, la Ley 26.061 de Protección Integral de los Derechos de los Derechos de los Niños, Niñas y Adolescentes en el año 2005 y en el año 2006 de su decreto reglamentario, la que en idéntico sentido recepta el derecho a opinar y ser oído.

Que a partir de la Convención mencionada el concepto de capacidad del niño comienza a apartarse de parámetros fijos, determinados por la edad cronológica hasta poder afirmar hoy que habitamos ese cambio de paradigma que implica salir de la concepción del menor como objeto de derecho para considerarlo como sujeto de derechos. En este sentido, el Código Civil y Comercial adscribe a este modelo e introduce el concepto de capacidad progresiva, determinado no solo por su edad sino por el grado de madurez suficiente. Así, el art 24 establece que (...) son incapaces de ejercicio (...) b) la persona que no cuenta con la edad y grado de madurez suficiente con el alcance dispuesto en la sección $2^{\circ}$ de este Capítulo y el art. 26 que (...) la persona menor de edad ejerce sus derechos a través de sus representantes legales (...) la que cuenta con edad y grado de madurez suficiente puede ejercer por sí los actos que le son permitidos por el ordenamiento jurídico. (Stilerman, 2016). 
Consecuentemente el derecho del niño a expresar su opinión en todos los asuntos que le conciernen, aun cuando su opinión no sea vinculante, aparece como coralario de esta concepción del niño como sujeto de derecho.

La Convención sobre los Derechos del Niño, al respecto dispone en su artículo 12.1 que: “Los Estados Partes garantizarán al niño que esté en condiciones de formarse un juicio propio, el derecho de expresar su opinión libremente en todos los asuntos que afectan al niño teniéndose debidamente en cuenta las opiniones del niño, en función de la edad y madurez del niño. Con tal fin, se dará en particular al niño oportunidad de ser escuchado en todo procedimiento judicial o administrativo que afecte al niño, ya sea directamente o por medio de un representante o de un órgano apropiado, en consonancia con las normas de procedimientos de la ley nacional." Derecho que se vincula íntimamente con los reconocidos en los artículos $13^{\circ}$ y $14^{\circ}$ de la misma Convención, los derechos a la libertad de expresión y libertad de pensamiento. En la misma línea, el art. 27 de la Ley 26.061, establece que "el niño tiene derecho a ser oído ante la autoridad competente cada vez que lo solicite, a que su opinión sea tenida en cuenta al momento de resolver, a ser asistido por un letrado preferentemente especializado en niñez y adolescencia desde el inicio del procedimiento judicial o administrativo que lo incluya, y en caso de carecer de recursos el Estado deberá asignarle de oficio un letrado que lo patrocine, a participar activamente en todo el procedimiento, a recurrir ante el superior frente a cualquier decisión que lo afecte".(Assef, 2014).

En relación con el derecho del niño a ser escuchado, la Corte Interamericana de Derechos Humanos también se ha pronunciado en la misma línea, cuando indicó que era fundamental que "... los niños con discapacidad sean escuchados en todos los procedimientos que los afecten y que sus opiniones se respeten de acuerdo con su capacidad de evolución..." en el caso "Furlan y familiares vs. Argentina" (Beloff, 2018).

Continuando con la delimitación del marco normativo, el Código Civil y Comercial de la Nación, se ocupa expresamente del derecho del niño a ser oído, cuando en su art. 595 los ubica por encima de los derechos de los adultos involucrados, exigiendo que su opinión sea tenida en cuenta según su edad y grado de madurez, y estableciendo como obligatorio el consentimiento del niño cuando haya cumplido los 10 años. En su art. 653 inc. C. cuando explícitamente establece que la opinión del niño es un aspecto que, junto a otros, ha de ser ponderada por el Juez para el supuesto excepcional de resolver sobre el cuidado personal unilateral. En el Art. 706 donde establece que en toda decisión dictada en un proceso que afecte a los niños, niñas o adolecentes debe tener en cuenta su interés superior. Y en el art. 707 donde establece que las niñas, niños y adolescentes deben ser oídos en todos los procesos que los afecten. Y su opinión debe ser tenida en cuenta.

Así podemos arribar a una primera conclusión no menos conocida por todos pero que abre el camino que se pretende transitar en el presente trabajo, y es que es que la obligación de escuchar al menor tiene rango constitucional a mas del reconocimiento interno y regional incluso.

\section{El caso}

El fallo dictado por el Supremo Tribunal de Justicia de la Provincia de Río Negro tiene origen en el recurso de casación interpuesto por la progenitora del menor en cuestión en contra de la sentencia de la Cámara de Apelaciones que confirma la sentencia de primera grado que hizo lugar a la demanda planteada por el progenitor, otorgándole 
el cuidado personal unilateral a éste. Que la accionante funda su cuestionamiento a la sentencia recurrida en el hecho de que la misma tuvo lugar habiéndose omitido citar al adolescente para ser oído. El Alto Tribunal, atinadamente, decide que existen razones para que el recurso prospere y esto nos conduce a analizar con profundidad este derecho receptado por la normativa interna e internacional cuyo reconocimiento en pacifico incluso en la doctrina y jurisprudencia de nuestro país.

El derecho de Niños, Niñas y Adolescentes a ser escuchado en todo procedimiento judicial o administrativo que lo afecte comprende el derecho a ser oído y que su opinión sea tenida en cuenta. En cuanto a su alcance, el mismo fue precisado por la Observación General 12/2009 del Comité sobre los Derechos del Niño. “El párrafo 2 del artículo 12 especifica que deben darse al niño oportunidades de ser escuchado, en particular "en todo procedimiento judicial o administrativo que afecte al niño". El Comité recalca que esta disposición es aplicable a todos los procedimientos judiciales pertinentes que afecten al niño, sin limitaciones y con inclusión de, por ejemplo, cuestiones de separación de los padres, custodia, cuidado y adopción, niños en conflicto con la ley, niños víctimas de violencia física o psicológica, abusos sexuales u otros delitos, atención de salud, seguridad social, niños no acompañados, niños solicitantes de asilo y refugiados y víctimas de conflictos armados y otras emergencias. Los procedimientos administrativos típicos serían, por ejemplo, decisiones sobre la educación, la salud, el entorno, las condiciones de vida o la protección del niño. Ambos tipos de procedimientos pueden abarcar mecanismos alternativos de solución de diferencias, como la mediación o el arbitraje" (Apartado 32) "No se puede escuchar eficazmente a un niño cuando el entorno sea intimidatorio, hostil, insensible o inadecuado para su edad. Los procedimientos tienen que ser accesibles y apropiados para los niños. Debe prestarse especial atención al suministro y la transmisión de información adaptada a los niños, la prestación de apoyo adecuado para la defensa de los intereses propios, la debida capacitación del personal, el diseño de las salas de tribunal, la vestimenta de los jueces y abogados y la disponibilidad de pantallas de protección visual y salas de espera separadas" (Apartado 34).

No basta con oír al niño, sino que es preciso escucharlo. Escuchar su opinión equivale a reconocerlo como sujeto de derecho y no como objeto de protección. Este derecho a ser oído se encuentra dentro del marco del derecho a participar, esto es, la obligación de tener en cuenta su opinión al momento de tomar una decisión que lo involucre, es decir, tener en cuenta su voluntad real. Este Código pone fin a las diferencias de opiniones enrolándose en una tesis amplia según la cual todo niño, niña o adolescente debe ser escuchado personalmente por el juez (Herrera, 2015).

La opinión del niño no ha de ser vinculante en el sentido que nos explica Aida Kemelmajer de Carlucci (1994) al decir y aclarar que oír al menor no implica aceptar su deseo incondicional mente, su palabra no se convierte en sentencia; si no que el juez es quien va a resolver priorizando el interés superior del niño, y para tomar esta decisión tendrá en cuenta los argumentos del niño, lo que no significa atenerse a ellos.

Que no se puede sostener de modo alguno que la negativa a escuchar al adolescente de autos por parte de la Cámara no sea arbitraria cuando la misma contraría todo el plexo normativo descripto. Que el reproche es doble al tiempo que se observa que la negativa se funda en las "barreras" de expresión derivadas de la discapacidad que tendría el menor de autos, so pena de evitar su "re victimización". 
Que al tiempo de ahondar en el análisis de la relación entre discapacidad y acceso a la justicia observamos rápidamente que encuentra garantías constitucionales que aseguran este último sino que además exige un rol de juez activo que remueva las trabas que impiden un real y efectivo acceso a la justicia. Así, la Convención de los Derechos de las Personas con Discapacidad establece en su Art. 13 que "Los Estados Partes asegurarán que las personas con discapacidad tengan acceso a la justicia en igualdad de condiciones con las demás, incluso mediante ajustes de procedimiento y adecuados a la edad, para facilitar el desempeño de las funciones efectivas de esas personas como participantes directos e indirecto (... )A fin de asegurar que las personas con discapacidad tengan acceso efectivo a la justicia, los Estados Partes promoverán la capacitación adecuada de los que trabajan en la administración de justicia (...) Y puntualmente, en lo que fuere objeto del presente, en cuanto al derecho a ser oído, el Art. 7.3 de la mencionada Convención "Los Estados Partes garantizarán que los niños y las niñas con discapacidad tengan derecho a expresar su opinión libremente sobre todas las cuestiones que les afecten, opinión que recibirá la debida consideración teniendo en cuenta su edad y madurez, en igualdad de condiciones con los demás niños y niñas, y a recibir asistencia apropiada con arreglo a su discapacidad y edad para poder ejercer ese derecho." En el actual modelo de discapacidad de derechos humanos e igualdad inclusiva, al que se inscribe nuestro ordenamiento interno, en el decir de la Observación General N 6/2018 cuando establece que (Los Estados) deben adoptar medidas de apoyo a fin de que todos los niños con discapacidad puedan ejercer su derecho a ser escuchados en todos los procedimientos que los afectan, incluso en los parlamentos, comités y órganos de adopción de decisiones políticas, no es posible sostener la falta de convocatoria del adolescente para ser escuchado por el juez del proceso.

Que así las cosas podemos observar que el adolescente se encuentra en un doble estado de vulnerabilidad lo que requiere de un rol activo de los tribunales, que se remuevan esas barreras, los ajustes necesarios para dar cabida a la diferencia como aspecto de la dignidad humana, tomando las palabras de la Observación General 6/2018 del Comité de las personas con discapacidad que adscribe a un modelo de discapacidad basado en derechos humanos e igualdad inclusiva. Las Reglas de Brasilia sobre Acceso a la Justicia de las personas en condiciones de vulnerabilidad se ocupa puntualmente de ello cuando en la Regla 3 establece que "se consideran en condición de vulnerabilidad aquellas personas que, por razón de su edad, género, estado físico o mental, o por circunstancias sociales, económicas y éticas y/o culturales, encuentran especiales dificultades para ejercitar con plenitud ante el sistema de justicia los derechos reconocidos por el ordenamiento jurídico" Así las cosas, se hace necesario juzgar con la conocida "perspectiva de vulnerabilidad" y que en el caso concreto se simplifiquen los procesos y flexibilicen las formas cuando están involucrados personas con discapacidad.

Así las cosas pues bien, si se había observado que la escucha en la primera instancia no había sido eficiente de modo que haga presuponer una respuesta negativa o imposibilidad de expresión en esta oportunidad, será tarea de la Cámara el generar el ambiente propicio, seguro y funcional para que el juez valore la opinión del adolescente sobre el asunto.

La Cámara podría haberse valido de la ayuda de las ciencias auxiliares. Un niño se expresa no sólo en la palabra sino también a través de dibujos, juego, síntomas y reacciones, tomando el juzgador en consideración también las manifestaciones no verbales del adolescente. 


\section{Reflexión final:}

El presente comentario constituye una invitación a reflexionar acerca de la deuda pendiente todavía existente con aquellas personas que se encuentran en una condición de vulnerabilidad, cuanto resta por aprender del modelo en el que se inscribe el acceso a la justicia actual.

Desde una perspectiva de derechos humanos, el modelo actual de acceso a la justicia supone la obligación del Estado y puntualmente del Poder Judicial de contrarrestar todas aquellas circunstancias sociales, económicas, personales, y de cualquier otro tipo que pudieran, en la práctica, dificultar o impedir a las personas acceder al amparo de la justicia. Se requiere e impone un deber de diligencia especial por parte de los tribunales cuando se trata de personas vulnerables, el interés de estas constituye una normativa de orden público en aras a su protección, es decir que los poderes del juez se amplían al servicio de los intereses que han de ser tutelados por la función de garante que nos convoca.

\section{REFERENCIAS BIBLIOGRÁFICAS}

- Assef, M.S. (2014). El Tiempo de los niños. Derechos fundamentales del niño a la luz de los nuevos paradigmas. [Versión Electrónica] Revista Jurídica La Ley. DJ10/12/2014,1. Cita online: AR/DOC/3371/2014

- Beloff, Mary. Derechos del niño. Su protección especial en el Sistema Interamericano. Hammurabi. Pág. 307 a 310.

- Herrera, N.S., (2015). La participación del niño a la luz de la CDN, las legislaciones de protección integral de derechos y el Proyecto de Código Civil y Comercial. [Versión Electrónica] Revista Jurídica La Ley 2015 (abril), 06/04/2015 cita online: AR/DOC/874/2015

- Kemelmajer de Carlucci, A., (1994) El derecho constitucional del menor a ser oído. Revista de derecho privado y comunitario N²7. Pag.157 a 187

- Stilerman, Marta (2016) Teoría y Práctica del Derechos de los Niños. Cathedra Jurídica. Págs. 1 a 5.237 a 256. 